\title{
LOS LÍMITES DE LA INTERPRETACIÓN. FREUD, RELEÍDO A PARTIR DE GADAMER
}

\author{
Niklas BORNHAUSER \\ Universidad de Wurzburgo
}

\begin{abstract}
RESUMEN. Se discute la posible relación, susceptible de ser establecida, entre el enrevesado pensamiento de H.-G. Gadamer y el psicoanálisis freudo-lacaniano a partir de la respectiva problematización del lenguaje y las consecuencias teórico-prácticas que a partir de ella se desprenden. Arrancando de la justa consideración de la relevancia de la experiencia inaugural de lo inconsciente para el ulterior devenir del psicoanálisis, analizando algunas figuras claves para una aproximación desidentificada a la obra freudiana, se consideran las semejanzas estructurales de lo inconsciente con el lenguaje y se señalan los topes y límites de una práctica interpretativa apuntalada en una lectura comparativa entre hermenéutica filosófica e interpretación psicoanalítica.
\end{abstract}

Y lo que es el lenguaje (no lo que quiere decir ni la forma en que lo dice), lo que es en su ser, es esta voz tan tenue, esta regresión tan imperceptible, esta debilidad en el fondo y alrededor de cualquier cosa, de cualquier rostro, que baña en una misma claridad neutra - día y noche a la vez- el esfuerzo tardío del origen, la erosión temprana de la muerte.

(Michel Foucault, El pensamiento del afuera)

Los escritos de H.-G. Gadamer conforman un corpus textual rico y complejo, irreducible a un abordaje único. Su repercusión en la filosofía contemporánea en los últimos años ha sido retratada en numerosas ocasiones, de manera que actualmente se dispone de gran número de recepciones y reflexiones a partir tanto de su pensamiento como de su obra. Por consiguiente, dada la reciente proliferación de gran cantidad de textos secundarios, algunos de ellos de con- 
siderable magnitud y extensión, toda consideración de sus escritos ha de plantearse la pregunta por su respectiva pertinencia, su interés o aporte particular.

Es así como en este lugar lo que se pretende no es un examen pormenorizado del pensar de Gadamer, sino, más bien, la exposición de la relevancia de ciertos conceptos atribuidos al pensador de Marburgo para una lectura particular del psicoanálisis. Si bien, en términos generales, consideraba que "para cualquiera que se dedique a la psicología sigue siendo razonable ocuparse de la filosofía y sobre todo de los comienzos más antiguos del pensar griegon ${ }^{1}$, las alusiones directas de Gadamer, ya sea a la psicología o al psicoanálisis, son escasas y puntuales, generalmente se encuentran circunscritas a otros Leitprobleme o problemáticas directrices mayores o más globales. Por otro lado, quizá entre los textos que más abiertamente se hacen cargo de problemas tradicionalmente inscritos en el campo del psicoanálisis están "Behandlung und Gespräch», «Hermeneutik und Psychiatrie" y "Angst und Ängste", entre otros, reunidos en el tomo Über die Verborgenheit der Gesundheit. De la misma manera, la incidencia del pensar de Gadamer en el psicoanálisis no es la del impacto directo o de la presencia inmediata en las reflexiones de carácter psicoanalítico. Más bien, trataremos de ilustrar su relevancia para una determinada lectura de los textos de Sigmund Freud, que más bien es una relectura, y que da una especie de rodeo [Umweg] por la filosofía, la lingüística y la antropología estructural, a partir del cual los escritos freudianos se someten a una interpretación novedosa y desconcertante. Es decir, leeremos a Freud con Gadamer, destacando, de esta manera, el aporte decisivo y liberador que la hermenéutica de este último puede significar para el psicoanálisis freudiano, cuyo destino actualmente se debate entre la esterilidad sofocante de las lecturas ortodoxas y las exigencias imperantes de la neuropsiquiatría.

En otras palabras, se trata de establecer un diálogo [Gespräcb] a posteriori entre Gadamer y Freud, en el cual el movimiento de entrada consistirá en una interrogación hacia la teoría y clínica psicoanalítica considerando algunos postulados centrales de la obra de Gadamer. Las reflexiones siguientes se ubican, por lo tanto, a medio camino entre filosofía y psicoanálisis, dos dominios emparen-

1 «Für jeden, der Psychologie treibt, bleibt es sinnvoll, sich mit Philosophie und vor allem mit den ältesten Anfängen des griechischen Denkens zu beschäftigen" (H.-G. GADAMER: «Leben und Seele», Über die Verborgenheit der Gesundheit, Fráncfort del Meno: Suhrkamp, 1993, p. 176). 
tados pero, al fin y al cabo, nítidamente distinguibles y separables, que en ningún caso han de ser tratados como discursos homónimos o equivalentes ${ }^{2}$. La existente dificultad de diálogo entre filosofía y psicoanálisis probablemente se deba, al menos en parte, al hecho que la problematización del lenguaje y la inserción en el mismo transcurren de manera diferente y que el morar del filósofo en el lenguaje se ve perturbado visiblemente a partir del momento decisivo en el cual, con la publicación de Die Traumdeutung (1900 [1899]), el sueño hace su entrada en el campo de las significaciones y de ahí en adelante el filósofo se vea obligado a admitir que «no habita la totalidad de su lenguaje, como un dios secreto y omniparlante; descubre que hay, junto a él, un lenguaje que habla y del que no es dueño" ${ }^{3}$.

La experiencia de lo inconsciente, una experiencia en la cual se hace escuchar la locura, la muerte y la sinrazón, conformaría una seria amenaza para una serie de oposiciones características de la filosofía moderna en el sentido de neuzeitlich, tales como los pares libertad-restricción, autonomía-independencia, individuo-sociedad. Si, por un momento, se acepta la idea, sin duda sobresimplificada, aunque de innegable valor didáctico, de una oposición radical entre filosofía y psicoanálisis, entonces dicha relación de contradicción será mejor retratada por el binomio conceptual razón-sinrazón. De esta manera, el acto fundacional de la filosofía (moderna) - y su constante renovación-, la

2 El que el esporádico acercamiento entre ambas disciplinas en el pasado la mayoría de las veces se haya efectuado al modo de un diálogo entre sordos, a nuestro parecer, en parte se debe justamente a la incapacidad o falta de disposición por parte de ambos de escuchar al otro en su diferencia especifica, soportando esta différance sin ceder espontáneamente a la tentación de someter y dominar a aquel discurso ajeno, a incorporar y asimilarlo traduciéndolo a categorías y conceptos familiares. En estos casos, siguiendo la tesis central de Wabrheit und Methode, difícilmente se puede hablar de un auténtico comprender, pues se hecha de menos, en esta incapacidad de establecer un diálogo, la estructura inherente de pregunta y respuesta y la fusión de horizontes resultante, propia de la comprensión hermenéutica. En efecto, a pesar de todas las similitudes constatables, hay algo en la constitución relativa de ambas modalidades discursivas que, por más que intenten afinar el oído y atender a la singularidad del decir del otro, en última instancia las separa y aleja. Por ello, al revisar los contados momentos en los cuales se ha materializado la inquietud por conocer y comprender al otro en su singularidad irreducible, se ha impuesto la convicción de que no hay lenguaje común entre la filosoffa y el psicoanálisis, una intuición a cuyo esclarecimiento, al menos en parte, estará dedicada esta exposición.

${ }^{3}$ M. FoUCAULT, "Prefacio a la transgresión" en Entre filosofia y literatura, Obras esenciales, volumen I, Barcelona: Paidós, 1999, p. 172. 
imposición autoritaria e inapelable de la razón (moderna), se basa en la represión, la exclusión o expulsión de una serie de fenómenos que por su naturaleza rebelde e insurrecta constituirán una amenaza para el gobierno soberano de la razón recientemente instituida. Es como si el psicoanálisis enfatizara justamente algo que es constantemente producido y reproducido por la filosofía moderna - sin que ésta supiera conscientemente de ello-, a saber, su propio gesto fundacional, la supresión de la locura constitutiva, la referencia inherente a la sin-razón.

Es así como frente a la hegemonía de la razón moderna, establecida mediante la supresión forzosa de toda experiencia contraria capaz de cuestionar su inapelable autoridad, el psicoanálisis mediante la interpretación de los sueños y de las demás producciones psíquicas ha despertado, vuelto a despertar un incesante murmullo, que no cesa de increpar el frágil dominio de la razón. El psicoanálisis, en esta constelación, hace de portavoz, de vehículo o dispositivo del retorno [Wiederkehr] o regreso [Rückkehr]de lo reprimido, que recuerda a la cesura originaria, la partición establecida entre razón y no-razón.

La hipótesis que aquí se perfila sostiene que la preconcepción de lenguaje contenida ya en los mismos textos freudianos, juega un rol decisivo en el movimiento de aproximación y separación entre filosofía y psicoanálisis. Dicha hipótesis sólo puede ser sopesada suficientemente si se tiene en mente la contradicción elemental que caracterizaba la actitud y práctica teórica de Freud ante las ciencias modernas. Freud, un hombre decididamente ilustrado, un hombre que, a pesar de su resistencia a ser tributario de algún discurso anterior, deseaba con todas sus fuerzas ser un pensador ilustrado ejemplar, "se vio envuelto" en una experiencia que lo impulsó a abocarse a la tarea de la de(con)strucción de una serie de categorías del pensar establecidas por el pensamiento ilustrado.

En consecuencia, el psicoanálisis, en contra de su reciente apropiación por el discurso cientificista imperante, leído desde este lugar, hoy en día aparece como un discurso quebrado, discontinuo y fragmentado. Un discurso conflictuado, atravesado por múltiples rupturas y desgarraduras que, a segunda vista, más que volverse en contra de él y servir de pruebas de su falta de coherencia y de contundencia, resultan ser constitutivas de su misma modalidad tensionada y de su forma discursiva específica contrastante con la pretensión y vanidad de los gran- 
des metarrelatos ${ }^{4}$. Más allá de las distinciones escolásticas y las disputas ideológicas, el psicoanálisis se nos muestra como una auténtica práctica de la escucha y de la interpretación, y que ha sabido aproximarse a lo "verdaderamente psíquico" - - esto es, lo inconsciente- mediante la lectura y el desciframiento de las formas, dilucidando las diversas manifestaciones vueltas accesibles a la percepción.

\section{Hermenéutica filosófica y psicoanálisis freudiano: encuentros y desencuentros}

Si bien Sigmund Freud, principalmente debido a las restricciones y limitaciones históricas impuestas por su propio contexto cultural y académico, nunca hizo explícita, al menos a nivel «teórico», la incidencia de una tradición del pensamiento preocupada por construir una Kunstlebre des Verstehens, una enseñan$\mathrm{za}$, una doctrina, un sistema, un arte del comprender y de la comunicación, una hermeneutikè téchne, las relaciones susceptibles de ser establecidas entre el pensar de Hans-Georg Gadamer y el estratificado pensamiento de Sigmund Freud, fácilmente caracterizable como un laberíntico camino del pensar, animado por el deseo de alcanzar lo que probablemente se llamaría una "comprensión en el horizonte de la hermenéutican, son descubiertas de inmediato por una lectura atenta y sensible a las semejanzas estructurales.

La dificultad, ya señalada, en lo que respecta a la realización de esta tarea consiste en que las reflexiones freudianas acerca del lenguaje, probablemente debido a la influencia de sus maestros Brücke, Meynert y Exner, se mueven a un nivel pre-psicoanalítico, es decir, se encuentran desfasadas con respecto a aquellos textos en los cuales a posteriori se distingue una concepción implícita de la estructura y dinámica del lenguaje. Por ello, al momento de ilustrar la relevancia de la función y del campo del lenguaje, tan magníficamente trabajado por Gadamer, para el pensamiento freudiano, se aludirá, en más de una ocasión, al trabajo efectuado por Lacan sobre el terreno explorado por Freud, facilitando de esta manera las referencias recíprocas entre Gadamer y Freud. El mismo Gadamer, al pro-

4 Una lectura a posteriori del psicoanálisis freudiano devela que si éste no se ajusta a las exigencias y requisitos de las ciencias modernas, no es por un déficit, una merma, sino porque se ocupa precisamente de aquello que la ciencia se empeña en excluir para constituirse, una y otra vez, como tal. 
nunciarse con respecto al «rol fundamental» que la hermenéutica debía jugar en el marco del psicoanálisis, decía que «la hermenéutica y el círculo del lenguaje, que se cierra en el diálogo, [tienen] aquí su lugar, como creo haber aprendido sobre todo de J. Lacan" ${ }^{5}$, dando a entender con esta escueta alusión que al menos conocia la obra de Lacan.

Debido a la confusión resultante de las luchas de poder mantenidas en la actualidad entre las diversas interpretaciones del legado de Freud se hace necesario recordar que la experiencia freudiana originaria, una experiencia inaugurada por el descubrimiento de lo inconsciente y que permanecería unida indisolublemente a su constante producción, se da en su totalidad en el uso y ejercicio de la palabra, es decir, en el campo del lenguaje ${ }^{6}$. Si puede haber un "postulado metodológico fundamental", como indica N. Braunstein, éste ha de ser que "toda la experiencia del análisis pasa y debe pasar en el campo del lenguaje» ${ }^{7}$, de lo cual se deduce el siguiente principio "que guía a la técnica del análisis: crear las condiciones para el despliegue irrestricto de la palabra de modo que pueda emerger ese saber ignorado del que no es posible desdecirse" ${ }^{8}$.

La relevancia de la justa consideración del lenguaje en y para el psicoanálisis freudiano solamente puede ser apreciada si no se olvida que éste, en sus comienzos, se remonta no a la reflexión paciente y a la especulación teórica minuciosa,

5 «Die Hermeneutik und der Kreis der Sprache, der sich im Gespräch schließt, [hat] hier ihren Ort, wie ich vor allem aus J. Lacan gelernt zu haben meine» (H.-G. GADAMER: "Rhetorik, Hermeneutik und Ideologiekritik", Gesammelte Werke, vol. II, Tubinga: J. C. B. Mohr [Paul Siebeck], 1999, p. 249).

6 Como dice J. A. Miller (J. A. Miller: «Algorithmes de la psychanalyse», Ornicar?, número 16, 1978) a propósito del comentado "retour à Freud», la obra de Freud, en la medida en que los conceptos "inventados» por él, corregidos y multiplicados incesantemente, sólo encuentran su necesidad y razón al ser puestos en relación con la estructura del lenguaje, deviene ella misma una formación del inconsciente a leer, descifrar e interpretar. Es decir, la referencia a Freud, el gesto de ir a sus textos, un deber sine qua non para todo analista, es siempre ya un acto interpretativo, un intento productivo de distinguir y ubicar los conceptos que se perfilan en ellos en relación al todo siempre incompleto de la ensambladura o juntura de relaciones [Beziehungsgefüge], crecido históricamente, articulado por las relaciones recíprocas de significación, comprometido en un eterno proceso de re-composición.

${ }^{7}$ N. BRAUNSTEIN: "Lingüistería (Lacan, entre el lenguaje y la lingüística)" en El lenguaje y el inconsciente freudiano, ed. cit., p. 166.

${ }^{8}$ Ibíd., p. 167. 
sino a una experiencia sorprendente y desconcertante, inesperada y difícil de conceptualizar —esta es, claro está, la experiencia de lo inconsciente-. H.-G. Gadamer conocía y apreciaba esta particularidad, ya que alineaba a Freud, junto con Schopenhauer y Nietzsche, en una corriente del pensar que constantemente atravesaba y superaba las fronteras, deudoras de la herencia empírica del idealismo alemán, de la conciencia y de la conciencia de sí. Dicha experiencia, que acompaña al psicoanálisis a lo largo de su complejo y contorneado devenir, en última instancia, evoca el quehacer hermenéutico en su sentido más originario al remitir a aquello que «en toda orientación humana hacia el mundo se encuentra con el átopon, lo extraño, singular, raro, lo que no se deja alojar en ninguna parte en los órdenes acostumbrados de expectación de la experiencia» ${ }^{10}$.

El (des)encuentro con el átopon, el choque con aquello que "no da a lugar" o "no tiene cabida", la colisión con lo extraño y siniestro, lo que se sustrae y resiste a ser resumido bajo las categorías acostumbradas y establecidas de la experiencia y del pensamiento, justamente debido a su efecto interrogante sobre las estructuras avaladas del conocer, en la historia del psicoanálisis se perfila como uno de sus momentos más productivos y más fecundos. Si la empresa freudiana, criticada, distorsionada y sobresimplificada hasta la irreconocibilidad tanto por sus detractores como por sus seguidores, tiene algo de llamativo y de novedoso, entonces aquel carácter innovador y cuestionador del saber y de las prácticas clínicas precedentes se debe, en gran medida, a la inquietud despertada en Freud a propósito de su encuentro con lo fuera de lugar, lo extraño y desconcertante, lo inasimilable por las expectativas traídas de antaño y las categorías apriorísticas de la experiencia. Coincide en esto con la experiencia de mundo [Welterfahrung] propiamente humana, que Gadamer designa como hermenéutica, y en la cual "la experiencia hace su entrada como algo nuevo, que echa por tierra lo que había guiado nuestras expectativas y que en aquel derribar se pone en su sitio a sí mismo» ${ }^{11}$. Nuestro propio

9 Véase H.-G. GADAMER: «Leben und Seele», ed. cit., p. 176-177.

${ }^{10}$ "In aller menschlichen Weltorientierung als das atopon, das Seltsame begegnet, das sich in den gewohnten Erwartungsordnungen der Erfahrung nirgends unterbringen läßt» (H.-G. GADAMER: «Rhetorik, Hermeneutik und Ideologiekritik», Gesammelte Werke, vol. II, Tubinga: J. C. B. Mohr [Paul Siebeck], 1999, p. 237-8).

11 "Die Erfahrung eintritt als etwas Neues, das umstößt, was unsere Erwartungen geleitet hatte, und das sich im Umstoßen selbst neu einordnet" (H.-G. GADAMER: "Die Universalität des hermeneutischen Problems", Gesammelte Werke, vol. II, Tubinga: J. C. B. Mohr [Paul Siebeck], 1999, p. 230). 
experienciar del mundo solamente puede ser ampliado y enriquecido si, a partir del mundo interpretante, articulado por sus respectivas referencias de reciprocidad, damos el paso hacia lo ajeno, nos abrimos a la experiencia de lo extraño.

La hipótesis al respecto es que lo estrictamente distintivo del hacer y pensar de Freud, su irreducible e indispensable plus-de-sentido, solamente puede ser pensado con justicia ante el horizonte de una práctica revolucionaria, subversiva, que busca activamente y sabe aguantar el choque inquietante con lo ajeno y lo extraño, lo que, pareciendo proceder de una exterioridad absoluta, impacta y remueve al sujeto en su más "profunda» intimidad. La práctica inaugurada por Freud, en ese sentido, sería una práctica fronteriza, liminar, que se halla realizada plenamente donde son subvertidas las categorías tradicionales del quehacer práctico y del pensar. El psicoanálisis freudiano, entonces, será aquella modalidad discursiva dispuesta a aceptar incondicionalmente el desafío de pensar lo impensable, de soportar el cuestionamiento "de fondo" de sus propios supuestos y fundamentos por la irrupción intempestiva e impredecible, que conlleva siempre la sorpresa y el desconcierto. Esta experiencia intempestiva nos induce a lanzarnos a la búsqueda de la palabra, mejor dicho, de la expresión [Ausdruck] justa, que nos permita sujetarnos a ella, encontrar un sostén fiable en medio del torrente del acontecer ominoso en cuya incomprensibilidad corremos peligro de perder la orientación e incluso de padecer nuestra propia aniquilación.

\section{El lenguaje de los sueños}

Hechas estas aclaraciones previas, destinadas a subrayar que toda la obra de Freud, inaugural en el campo del inconsciente, está inscrita en la problemática del lenguaje, se dará paso a la consideración parcial, pero pormenorizada, de ciertos pasajes textuales, inscritos en momentos históricos particulares, que testimonien la presencia e incidencia del lenguaje en el pensar de Freud. La elección de dichos fragmentos de texto, por cierto, no es cosa fácil, pues, como ya observó J. Lacan a principios de los años setenta,

la obra completa de Freud nos presenta una página de cada tres de referencias filológicas, una página de cada dos de inferencias lógicas, y en todas partes una aprehensión dialéctica de la experiencia, ya que la analítica del len- 
guaje refuerza en ella más aún sus proposiciones a medida que el inconsciente queda más directamente interesado ${ }^{12}$.

En primer lugar, sostenemos que La interpretación de los sueños (1900 [1899]), La psicopatologia de la vida cotidiana (1901) y El chiste y su relación con lo inconsciente (1905) conforman, en su unidad, lo que F. Saal en su momento denominó «un gran fresco inaugural», regocijante por el descubrimiento que colocará al psicoanálisis en el campo más amplio de los fenómenos de la cultura, abriendo ventanas indicadas ya desde antes, cuando dominaba la preocupación por entender al síntoma, a la enfermedad. En particular, Die Traumdeutung (1900 [1899]) ${ }^{13}$, al sugerir que "el sueño tiene la estructura de una frase, o más bien, de un rébus, es decir de una escritura" ${ }^{14}$, ilustra con especial claridad cuál es el tipo de realidades a las que se aplicará el psicoanálisis - realidades discursivas-.

El sentido atribuido a las producciones oníricas, hasta entonces desdeñadas y postergadas por la razón especulativa, la comprobación de la implicación acti-

12 J. LACAN: "La instancia de la letra en el inconsciente o la razón desde Freud» (1957), en Escritos 1, ed. cit., p. 489. ("L'œuvre complète de Freud nous présente une page sur trois de références philologiques, une page sur deux d'inférences logiques, partout une appréhension dialectique de l'expérience, l'analytique langagière y renforçant encore ses proportions à mesure que l'inconscient y est plus directement intéressé" [J. LACAN: "L'instance de la lettre dans l'inconscient ou la raison depuis Freud (1957)» en Ecrits, ed. cit., p. 509]).

${ }^{13}$ A pesar de estar datada anticipatoriamente con la fecha del nuevo siglo, la aparición de esta obra acontece a comienzos de noviembre de 1899 , siendo que lo esencial de La interpretación de los sueños había quedado terminado ya a comienzos de 1896, demorando su redacción definitiva hasta el verano de 1899 , fecha que, si se toman en cuenta los innumerables pies de página, incluso puede ser extendida hasta su muerte. Ello se explica, al menos parcialmente, por la creciente preocupación de Freud por el estilo y los aspectos estéticos, tanto de la escritura en general como de su propia labor productiva en particular, como él mismo manifiesta en una carta a Wilhelm Fliess: "Creo que mi autocrítica no era del todo injustificada. En algún lugar de mi ser se escondía una sensibilidad hacia la forma, una valoración de la belleza como una suerte de perfección, y las frases de mi libro sobre los sueños, retorcidas, ufanas de sus giros indirectos y que miran de soslayo a los pensamientos, han inferido grave afrenta a un ideal dentro de mí. Difícilmente me equivoqué, entonces, si concibo esa falla formal como signo de deficiente dominio del material». (FREUD, S.: Carta 119, Obras Completas, vol. IV, ed. cit., p. 13).

14 J. LACAN: "Función y campo de la palabra y del lenguaje en psicoanálisis (1953)" en Escritos 1, Buenos Aires: Siglo XXI, 1971, p. 256-7. ("Le rêve a la structure d'une phrase, ou plutôt, à nous en tenir à sa lettre, d'un rébus, c'est-à-dire d'une écriture" [J. LACAN: «Fonction et champ de la parole et du langage en psychanalyse» (1953), en Ecrits, París: Seuil, 1966, p. 267]). 
va del deseo en su misma gestación, el análisis del «trabajo del sueño», trabajo producto de la necesidad de enmascaramiento o disfraz del mismo, las teoretizaciones acerca de un auténtico "lenguaje del sueńo" y, lo que probablemente haya sido el aporte más decisivo, a saber, la puesta en práctica de la inacabable tarea interpretativa, iniciada con el desciframiento del sueño, son algunos de los efectos de la exploración del "continente oscuro" ${ }^{15}$. En otras palabras,

es en la versión del texto donde empieza lo importante, lo importante de lo que Freud nos dice que está dado en la elaboración del sueño, es decir en su retórica. Elipsis y pleonasmo, hipérbaton o silepsis, regresión, repetición, aposición, tales son los desplazamientos sintácticos, metáfora, catacresis, antonomasia, alegoría, metonimia y sinécdoque, las condensaciones semánticas, en las que Freud nos enseña a leer las intenciones postentatorias o demostrativas, disimuladoras o persuasivas, retorcedoras o seductoras, con las que el sujeto modula su discurso onírico ${ }^{16}$.

${ }^{15}$ La interpretación guarda una estrecha relación con el Proyecto de psicología para neurólogos (1950 [1887-1902]), en especial en los siguientes puntos que aparecen como elementos importantes y destacados en ambos textos: primero, el carácter de cumplimiento de deseo de los sueńos, elemento crucial al momento de aproximarse interpretativamente o con un afán comprensivo a estos; segundo, la naturaleza alucinatoria de los mismos, criterio indispensable para establecer, por un lado, su relación con la realidad material y, por el otro, con la realidad psíquica; tercero, el funcionamiento regrediente de la psique, sea entendido desde un punto de vista evolutivo o meramente lógico; cuarto, el descubrimiento de los mecanismos de desplazamiento y condensación, artilugios imprescindibles para la comprensión de los aspectos anímicos y formales en relación al funcionamiento de la psique; quinto, la similitud entre los sueños y los síntomas neuróticos; y sexto, la distinción entre proceso primario y secundario. La diferencia esencial entre ambos escritos la constituye la incorporación del complejo de Edipo, cuya existencia recién fue establecida durante el verano y el otofio de 1897 (cartas 64 a 71), probablemente efecto del autoanálisis de Freud, tal como se desprende del análisis de la carta 71.

16 J. LACAN: «Función y campo de la palabra y del lenguaje en psicoanálisis (1953)» en Escritos 1 , ed. cit., p. 257. («C'est à la version du texte que l'important commence, l'important dont Freud nous dit qu'il est donnée dans l'elaboration du rêve, c'est-à-dire sans sa rhétorique. Ellipse et pléonasme, hyperbate ou sylepse, régression, répétition, apposition, tels son les déplacements syntaxiques, métaphore, catachrèse, antonomase, allégorie, métonymie et synecdoque, les condensations sémantiques, où Freud nous apprend à lire les intentions ostentatoires ou démonstratives, dissimulatrices ou persuasives, rétorsives ou séductrices, dont le sujet module son discours onirique» [J. LACAN: "Fonction et champ de la parole et du langage en psychanalyse (1953)» en Ecrits, ed. cit., p. 267-7]). 
Por lo tanto, si el trabajo del sueño sigue las leyes del significante se vuelve comprensible que Freud, mediante Die Traumdeutung (1900 [1899]) no haya pretendido develar otra cosa que las leyes de lo inconsciente en su extensión más general. En otro texto, Lacan afirma que

si [Freud] nos ha enseñado a seguir en el texto de las asociaciones libres la ramificación ascendente de esa estirpe simbólica, para situar por ella en los puntos en que las formas verbales se entrecruzan con ella los nudos de su estructura - queda ya del todo claro que el síntoma se resuelve por entero en un análisis del lenguaje, porque él mismo está estructurado como un lenguaje, porque es lenguaje cuya palabra debe ser librada ${ }^{17}$.

Consiguientemente, se sostiene que el aforismo lacaniano de «lo inconsciente estructurado como un lenguaje» ${ }^{18}$ sitúa al pensamiento psicoanalítico, por un lado, en oposición a la ego psychology de Hartmann, Abraham y Winicott, inspirada en el credo de las ciencias empíricas, preocupada de fortalecer el yo y sus funciones, de hacer consciente lo inconsciente, $y$, por el otro, lo coloca en íntima vecindad de las reflexiones de Gadamer acerca del lenguaje como medio [Mitte] de la experiencia humana, la necesaria historicidad del comprender, el análisis del Dasein y la antropología existencial ${ }^{19}$.

Probablemente, desde esta segunda posición, leyendo a Freud en perspectiva, como un pensador heredero y deudor de su tiempo, se pueda sugerir a

17 J. LACAN: «Función y campo de la palabra y del lenguaje en psicoanálisis» (1953), en Escritos 1 , ed. cit., p. 258. ("S'il nous a appris à suivre dans le texte des associations libres la ramification ascendante de cette lignée symbolique, pour y repérer aux points où les formes verbales s'en recroisent les nouds de sa structure, il est déjà tout à faire clair que le symptôme se résout tout entier dans une analyse de langage, parce qu'il est lui-même structuré comme un langage, qu'il est langage dont la parole doit être délivrée" [J. LACAN: "Fonction et champ du parole et du langage en psychanalyse" (1953) en Ecrits, ed. cit., p. 269]).

${ }_{18}$ Con respecto a esta célebre sentencia, véase, por ejemplo, J. LACAN: Le Séminaire. Livre XI. Les quatre concepts fondamentawx, París: Seuil, 1973, p. 23.

${ }^{19}$ Véase G. CondRaU: Medizinische Psychologie, Olten: Walter, 1968. H.-G. GADAMER: Über die Verborgenheit der Gesundheit, Fráncfort del Meno: Suhrkamp, 1993. A. LORENZER: Úber den Gegenstand der Psychoanalyse oder: Sprache und Interaktion, Fráncfort del Meno: Suhrkamp, 1973; Sprachzerstörung und Rekonstruktion, Fráncfort del Meno: Suhrkamp, 1970. D. WYSS: Der Kranke als Partner, 2 tomos, Gotinga: Vandenhoeck \& Ruprecht, 1982. 
posteriori y a la luz de las varias e importantes revisiones de su obra, una distinción conceptual implícita en sus escritos: por un lado, el lenguaje, que se encuentra más próximo al habla, a la enunciación y la dicción, en fin, al discurso [Rede], entidad cuasi-material, pensada según criterios que reducen la palabra a un mero signo y envoltura de algo pre-pensado, pre-sabido y preconsciente, que ya ha efectuado y concluido una profusa labor noética; y por el otro, la linguiisticidad [Sprachlichkeit], medio simbólico del hombre, morada del ser. Por decirlo en pocas palabras, si la primera expresión remite a la primera tópica, a la escuela de Helmholtz, a Du Bois-Reymond, Ludwig y Brücke, a la concepción biomédica del hombre, a las secuelas de las incursiones freudianas en la neurofisiología y la neuroanatomía, al fisicalismo y el círculo de Viena, a las interpretaciones, interesantes a su manera pero parciales, de Alfred Lorentzer ${ }^{20}$ y de Jürgen Habermas ${ }^{21}$, la segunda alude a las posibilidades abiertas por los textos "culturales" de Freud, la segunda tópica, la lectura del psicoanálisis hecha por Lacan, la influencia del «segundo" Heidegger en éste, la ubicación del discurso psicoanalítico en vecindad de la antropología, el linguistic turn, el proyecto hermenéutico lanzado por Hans-Georg Gadamer y la creciente relevancia del concepto de lenguaje en la filosofía contemporánea.

A partir de la interpretación de los sueños, ésta en psicoanálisis siempre será una interpretación incompleta, no tanto por su eventual insuficiencia o deficiencia, sino en tanto interpretación trunca, manca, en falta. Este carácter incompleto ya es advertido por Freud en La interpretación de los sueños (1900 [1899]) y ello en dos sentidos. En primer lugar, por su evidente multivocidad, su compleja composición por capas [Vielschichtigkeit], el hecho de que en él frecuentemente se reúnan varios cumplimientos de deseo, a ratos contradictorios e inconciliables entre sí, y que estos deseos mediante una labor de estratificación geológica puedan constituir las múltiples capas tectónicas y sedimentos pétreos que componen la amalgamada estructura del sueño. Ya en la primera edición de Die

${ }^{20}$ A. LORENTZER: Zur Begründung einer materialistischen Sozialisierungstheorie, Fráncfort del Meno: Suhrkamp, 1972; Uber den Gegenstand der Psychoanalyse oder: Sprache und Interaktion, Fráncfort del Meno: Suhrkamp, 1973; Sprachstörung und Rekonstruktion, Fráncfort del Meno: Suhrkamp, 1973.

${ }^{21}$ Véanse especialmente los capitulos «Selbstreflexion als Wissenschaft: Freuds psychoanalytische Sinnkritik», "Das szientistische Selbstmißverständnis der Metapsychologie. Zur Logik allgemeiner Interpretation" y "Psychoanalyse und Gesellschaftstheorie. Nietzsches Reduktion der Erkenntnisinteressen", en J. Habermas: Erkenntnis und Interesse, ed. cit., pp. 262-364. 
Traumdeutung (1900 [1899]), al analizar las dificultades interpretativas que creaba la exhaustiva labor de la condensación, Freud advertía

que en rigor nunca se está seguro de haber interpretado un sueño exhaustivamente; aun cuando parece que la resolución es satisfactoria y sin lagunas, sigue abierta la posibilidad de que a través de ese mismo sueño se haya insinuado otro sentido ${ }^{22}$.

Esta primera objeción tendría relación con la naturaleza inagotable de la interpretación, en la cual, efectivamente, mediante el trabajo interpretativo son producidas nuevas significaciones, sin embargo, siempre insuficientes para agotar el sentido de un texto plástico, prolífico y hasta exuberante en significaciones. En este lugar, Freud se encuentra con Gadamer, quien en Wabrheit und Methode, al examinar la relevancia hermenéutica de la distancia temporal, afirma:

La extracción del verdadero sentido que se haya depositado en un texto o en una creación artística, no llega a su clausura en algún lugar, sino que en realidad es un proceso infinito ${ }^{23}$.

Empero, el propio Freud encuentra otra objeción a la interpretación íntegra y exhaustiva del sueño, menos relacionada con la incontenible proliferación epidémica del sentido. Este segundo argumento en contra de un agotamiento interpretativo del sentido, la generación de una interpretación "total», sin restos ni residuos a interpretar, parte de la consideración de un elemento destacado al interior del denso tejido onírico, a saber, su ombligo.

Es a propósito de la interpretación del sueño de la inyección de $\operatorname{Irma}^{24}$ que Freud, ante la estupefacción producida por la visión aterradora de la mancha

${ }^{22}$ S. FREUD: La interpretación de los sueños (1900 [1899]), Obras Completas, vol. IV, ed. cit, p. 287.

23 "Die Ausschöpfung des wahren Sinns aber, der in einem Text oder in einer künstlerischen Schöpfung gelegen ist, kommt nicht irgendwo zum Abschluß, sondern ist in Wahrheit ein unendlicher Prozeß». (H.-G. GADAMER: Wahrheit und Methode, Gesammelte Werke, vol. I, Tubinga: J. C. B. Mohr [Paul Siebeck], 1999, p. 303).

${ }^{24}$ S. FREUD, op. cit., pp. 128-41. 
blanca situada en la garganta de su paciente, se ve obligado a reconocer que "todo sueño tiene por lo menos un lugar en el cual es insondable, un ombligo por el que se conecta con lo no conocido" ${ }^{25}$. Algo que se resiste a ser interpretado. Lo que Freud ve al fondo, y con el fondo de las cosas tiene que ver la visión que se le brinda, es "un espectáculo horroroso", unos cornetes recubiertos por una membrana blancuzca, y en los que se muestran «todas las significaciones de equivalencia, todas las condensaciones que [uno] pueda imaginar ${ }^{26}$. Por decirlo en otras palabras, todo se mezcla y se confunde en esa única imagen, representante de «lo más profundo del misterio», lo que nunca se ve y que por su mera imagen es capaz de provocar la más auténtica angustia.

La mancha en cuestión, de acuerdo al análisis concienzudo y pormenorizado que Freud ofrece a continuación de su relato, recuerda a la difteritis, una enfermedad que había padecido la hija de Freud un par de años antes. A la evidente preocupación por la salud de su hija a causa de esta afección, en este caso, se le ha de sumar el recelo suscitado a propósito de las mentadas escaras en los cornetes que, como se apresura en añadir, le recordaban la autoadministración de cocaína, en sus propias palabras, "para reducir unas penosas inflamaciones nasales" ${ }^{27}$. El uso terapéutico de la cocaína, como ha documentado Strachey, no solamente aceleró la muerte del propio Freud, sino que ya había causado la muerte de un amigo cercano, Ernst Fleischl von Marxow, a quien Freud había recomendado su inyección ${ }^{28}$. En la mancha de color blanco se condensan, pues, un serie de significados, entre ellos, de manera sobresaliente, la angustia y la muerte, indicando de esta manera un callejón sin salida.

${ }^{25}$ Ibíd., p. 132, n. 18.

26 J. LACAN: El yo en la teoría de Freud y en la técnica psicoanalitica (1954-55). Seminario 2, Buenos Aires: Paidós, 1992, p. 235.

${ }^{27}$ S. FreUD: La interpretación de los sueños (1900 [1899]), ed. cit., vol. IV, p. 132.

${ }^{28}$ En 1892, inmediatamente tras la muerte de Brücke, Freud a su cuarto hijo incluso le llego a poner el nombre de Ernst, probablemente como producto de una sobredeterminación entre Ernst Brücke, uno de los maestros más influyentes de Freud, y Ernst Fleischl von Marxow. P. Gay denomina el incidente con la cocaína como una «desdichada aventura [que] siguió siendo uno de los episodios más perturbadores de la vida de Freud. Sus sueños revelan una persistente preocupación relacionada con la cocaina y sus consecuencias». (P. GAY: Freud. Una vida de nuestro tiempo, Barcelona: Paidós, 1996, p. 70) 
Si no estoy muy equivocado, por todos los caminos que hasta ahora emprendimos llegamos a la luz, al esclarecimiento y a la comprensión plena; a partir de este momento en que pretendemos penetrar más a fondo en los procesos anímicos envueltos en los sueños, todas las señas desembocan en la oscuridad ${ }^{29}$.

Los sinuosos caminos de la interpretación, sin lugar a dudas, conducirían a llevar la problemática de lo inconsciente $-\mathrm{y}$, por supuesto, sus respectivas consecuencias para una concepción psicoanalítica de la psique-a un punto álgido, en el cual se vislumbraban los límites del prodigioso método analítico, hasta ahora aplicado con tanto éxito. Parecía haber algo en el seno de la misma interpretación que limitaba el alcance de la interpretación freudiana y que tenía que ver con el estatuto mismo de lo inconsciente. Freud propuso una designación para aquel punto ciego, relacionado con el origen y la imposibilidad de hallar un significante -metalingüístico- para designarlo: «lo Unerkannte, esto es, lo noreconocido; equivalente de lo reprimido primordial, de aquello con lo cual conecta el ombligo del sueńo" ${ }^{30}$.

Lo no-(re)conocido de Freud, es decir, lo innombrable, generado a su vez por la palabra, desgarradura del tejido del lenguaje, será el anticipo del Real lacaniano, en torno al cual se umbilican las cadenas significantes que, ocultándolo, lo protegen para mantenerlo en su estatuto de causa del discurso ${ }^{31}$. Dado lo anterior, lo no-(re)conocido es, al mismo tiempo, efecto de la represión primordial, aquella fase - supuesta- de la represión "que consiste en que a la agencia representante [Repräsentanz] psíquica (agencia representante-representación) de la pulsión se le deniega la admisión en lo consciente» ${ }^{32}$. Este proceso hipotético, llamado represión primordial [Urverdrängung], elemento imprescindible de la teoría

\footnotetext{
29 S. FrEUD: La interpretación de los sueños (1900 [1899]), ed. cit., vol. V, p. 506.

${ }^{30}$ D. GERBER: "La represión y el inconsciente", en N. Braunstein (ed.): La re-flexión de los conceptos de Freud en la obra de Lacan, ed. cit., p. 114.

${ }^{31}$ Lo Unerkannte es condición del discurso porque constituye «ese algo que se especifica por no poder ser dicho en ningún caso, cualquiera sea la aproximación, por estar, si uno puede expresarse así, en la raíz del lenguaje». (J. LACAN: "Respuesta de J. Lacan a una pregunta», en Suplemento de las Notas, Publicación interna de la Escuela Freudiana de Buenos Aires, núm. 1, noviembre de 1980, p. 127).

32 S. FREUD: La represión (1915), ed. cit., vol. XIV, p. 143.
} 
freudiana de la represión, tiene como consecuencia inmediata la conformación de una serie de representaciones inconscientes - lo reprimido primordial一.

Considerando lo anterior, es posible aseverar, entonces, que el sueño se apuntala en lo imposible de (re)conocer y que en esto no se distingue de lo reprimido primordial [das Unverdrängte]. Lo indecible, lo que no puede ser dicho ni escrito, es, por lo mismo, empleando una expresión de Lacan, aquello que no cesa de no escribirse, que no cesa de insistir en hallar su lugar -imposible- en el discurso. Represión primordial, angustia y muerte se anudan en un enrevesado entramado que aún espera ser desenrollado.

\section{Alcances y repercusiones}

Con respecto a los términos puestos en relación, en primer lugar, es posible decir que

la represión primordial es desvanecimiento del ser viviente tras el significante. Éste, además, inscribiéndolo en el registro simbólico, sitúa al sujeto en la anticipación constante de su muerte y hace de él portador de un saber - saber de la muerte- del que nada querrá saber ${ }^{33}$.

Es entonces la misma interpretación psico-analítica, que es siempre analysis, dilución, disolución, déliasion, separación, incluso liberación, desprendimiento, en el sentido de disolver una unión material, una atadura física o química, pero también, por el otro, de absolver de una obligación, de liberar, desatar y desanudar de un lazo o una ligadura moral, tal como sugiere el verbo dégagement, que a la vez puede ser empleado para designar la acción de (des)empeñar una prenda, una gage, la que produce aquello que excede el análisis, un sentido oculto que rebasa y sobrepasa la interpretación. Esto, como muestra el fragmento siguiente, ya lo sabía Freud:

Aun en los sueños mejor interpretados es preciso a menudo dejar un lugar en sombras, porque en la interpretación se observa que de ahí arranca una madeja de pensamientos oníricos que no se dejan desenredar, pero que

33 D. GERBER: "La represión y el inconsciente” en N. Braunstein (ed.): La re-flexión de los conceptos de Freud en la obra de Lacan, ed. cit., p. 123. 
tampoco han hecho otras contribuciones al contenido del sueño. Entonces ese es el ombligo del sueño, el lugar en que él se asienta en lo no conocido ${ }^{34}$.

Una madeja de pensamientos, un lioso entrelazamiento de encadenamientos significantes, un anudamiento, enlace o ligadura [Verknüpfung] imposible de disolver.

En segundo lugar, el ombligo del sueño representa el impenetrable nudo de sentido mediante el cual se testimonia el logro de la emancipación del niño, marca de su lograda separación de la fusión diádica que lo unía inseparablemente a la madre. El nudo, producto de la torsión del cordón umbilical, que es el ombligo, representa la autoridad incuestionable de un gesto definitivo e irreversible, un acto tan tajante como inapelable, decisivo para la constitución del sujeto y su inscripción en el mundo del lenguaje. En él no solamente confluyen y se anudan diversas tramas significantes, sino con él también se interrumpe y suspende el discurrir continuo y completo de lo Imaginario, sustituyéndolo por la lógica de lo Simbólico.

De esta manera, hay en cada sueño, por mucho que el intérprete se empeñe en tornar inteligibles hasta a sus elementos más nimios, más in-significantes, un tópos inaccesible, que ya no, como en caso de la condensación, se presenta como una frontera provisoria, una limitación temporal y pasajera, sino como la noche más oscura, lo desconocido impenetrable, absoluto y primordial ${ }^{35}$.

Tercero, por lo general, el concepto psicoanalítico de lo Inconsciente es definido de otra manera — de lo Inconsciente se supone que es una entidad, una rea-

34 S. FREUD, op. cit., p. 519.

35 Esta distinción, por un lado, entre lo no conocido, pero que, una vez superadas las limitaciones circunstanciales del saber del analista, podrá ser revelado, vuelto consciente, y, por el otro, lo no conocible, incomprensible, inexplicable, es, se cree, una distinción fundamental para la comprensión del concepto de inconsciente en Freud y que reproduce, de manera aproximada, la distinción freudiana entre pre- e inconsciente. Lo preconsciente, como establecía Freud en 1915, a diferencia de lo inconsciente - que «a raíz del examen es rechazado por la censura, se le deniega el paso a la segunda fase; entonces se llamaba "reprimido" y tiene que permanecer inconsciente-", "no es aún consciente, sino susceptible de conciencia [según la expresión de J. BREUER]" (S. FREUD: Lo inconsciente (1915), ed. cit, vol. XIV, p. 169). El ombligo del sueño, de acuerdo a la distinción freudiana, sería una especie de inconsciente por excelencia, totalmente imposible de ser aprehendido por la conciencia. 
lidad (psíquica), por ejemplo, deseos perversos, prohibidos, acerca de la cual el sujeto debido a los mecanismos de defensa de la represión nada sabe (quiere saber)- - Esta concepción popular oscurece el rol decisivo del caso contrario: una entidad positiva, que no se caracteriza como un simple negativo de la conciencia, ni menos aún como las "profundidades" insondables del ser, sino que más bien paradojalmente sólo obtiene su consistencia sobre la base de un nosaber determinado -es decir, es su condición ontológica positiva que algo permanezca no-simbolizado, que algo no deba ser aprehendido en palabras-.

En fin, el omphalós del sueño, por lo tanto, se presentará como la más absoluta oscuridad; es, por decirlo de alguna manera, el reverso del relato del sueño, un punto ciego, imposible de enfocar mediante la interpretación. Y sin embargo, hay en el ombligo del sueño algo que se muestra, aunque sea sustrayéndose al análisis, y este algo es del carácter de lo primordial. Por ello el ombligo del sueńo en Freud, en la medida en que puede ser pensado como una anticipación de lo Real en Lacan, no es tanto un más allá invisible, que se oculta ante la mirada escrutinadora, engañando al intérprete mediante todo tipo de apariencias pérfidas e insustanciales, sino una mancha o un lugar vacío que distorsiona y altera la percepción «directa» de la realidad.

Lo Real, que se insinúa a través del ombligo del sueño, no es la verdad no simbolizable, indecible debido a su distante ubicación en la exterioridad más exterior, a la cual el sujeto, a pesar de todos sus esfuerzos, solamente se puede aproximar asintóticamente, sino aquella que torna incompleta, que yerra cualquier verdad simbólica articulada, que le imposibilita al sujeto hablante «decirlo todo». O sea, lo Real, lejos de situarse en la mera exterioridad al lenguaje, le es totalmente inherente a lo Simbólico y en ningún caso coincide con un más allá transcendental, un misterioso jenseits del lenguaje. Lo Real aludido entonces no puede ser designado no porque se encuentre en el exterior, afuera, más allá del orden simbólico, sino por ser inherente al mismo, por conformar su delimitación interna - lo Real es ese obstáculo interno que impide que el orden simbólico pueda «retornar a sí mismo», que pueda experimentar una identidad consigo mismo-.

Por lo tanto, lo que nos permite y hace hablar es justamente lo imposible de decir, lo que no puede ser nombrado, eso que es absolutamente discordante con el mismo lenguaje. Lo que nos enseña el ombligo del sueño es que el campo sim- 
bólico en realidad en sí siempre ya está agujereado, coartado, lisiado, estructurado en torno a un núcleo éxtimo, una imposibilidad lógica. Esta incapacidad del lenguaje de designar un elemento instalado en sus mismas entrañas, que se convierte en su limitación interior, es, por decirlo en el lenguaje de la psiquiatría, una genuina falla en la aprehensión de la realidad.

En torno a este vacío lingüístico que es el ombligo circulan, se desplazan y se condensan los eslabones dicharacheros del incesante movimiento del discurso. Dicho ombligo presenta, en ese sentido, una asombrosa coincidencia con el ser de Heidegger, el que, como éste insiste en remarcar una y otra vez, no es que esté simplemente sustraído, retirado o privado [entzogen], sino que el ser no «es» otra cosa que su propio sustraerse.

El anudamiento del ombligo, por otro lado, asegura la existencia de la distinción entre lo interior y lo exterior, sostiene la frontera divisoria, ya que de abrirse, el exterior, ajeno y hostil, inundaría la interioridad del psiquismo y, al mismo tiempo, el interior anímico se desparramaría en el exterior hasta confundirse insalvablemente con él. La ubicación liminar del ombligo, situado en la superficie de la piel, excluido en la interioridad, incluido en el exterior, es lo que lo caracteriza como un concepto expuesto a grandes tensiones, responsable de mantener la línea divisoria que delimita el aparato mental hacia afuera. Precisamente, en este lugar se cree encontrar su equivalencia con lo Real, en el pulsar de la sustancia pre- o protosimbólica en su horrible vitalidad, ya que éste irrumpe justamente en la frontera que separa el «interior» del «exterior".

En este sentido, se concluye que el descubrimiento de lo inconsciente, al poner en juego la estructura del lenguaje y la relación del hombre con el lenguaje, consiste en que "el alcance del sentido", lejos de circunscribirse a una transcripción literal, palabra por palabra, del discurso del sueño, «desborda infinitamente los signos manipulados por el individuo" ${ }^{36}$. Hay siempre un plusde-sentido, un exceso simbólico, límite ultimativo del proceso psicoanalítico, frontera infranqueable que viene dada por la naturaleza del comprender hermenéutico.

${ }^{36}$ J. LaCAN: Seminario 2. El Yo en la Teorla de Freud y en la Técnica Psicoanalitica (1954-1955), Buenos Aires: Paidós, 1983, p. 188. 
El límite de la interpretación, a su vez, se relaciona con la angustia, angustia causada por la imagen sońada de la mancha en la garganta de Irma, que no es otra cosa que una identificación de angustia, última revelación del «eres esto": eres esto, que es lo más ajeno y distante de ti, lo más informe. Imagen horrorosa, situada al fondo de la garganta de Irma, espectáculo espeluznante, indefinido, indescriptible. Imagen angustiante, que concentra la desconcertante revelación de lo Real en lo que tiene de menos transparente, de lo Real sin mediación simbólica alguna, de lo Real último, ante lo cual las palabras se detienen y todas las categorías del lenguaje fracasan, objeto de angustia por antonomasia.

De acuerdo a la hipótesis aquí sostenida, en escritos como Die Traumdeutung (1900 [1899]), Das Unheimliche (1919), Jenseits des Lustprinzips (1920) y otros más que no pueden ser comentados en este contexto, Freud en los mismos límites del psicoanálisis, en los cuales se entrelazan y con-funden represión primordial, angustia y muerte, inicia el giro decisivo del psicoanálisis, que es, en cierto sentido, una inversión desde las ciencias naturales, su método, sus procedimientos, sus regulaciones y sus ideales, a aquel tipo de razonamiento más emparentado con la literatura, la poesía, la mitología y la filosofía. Sin la notable sensibilidad de Freud hacia las inflexiones del lenguaje, su interés por el estudio sistemático de sus torsiones y su pasión por los idiomas, distingos que atraviesan toda su obra desde Zur Auffassung zur Aphasien (1891) hasta Der Mann Moses und die monotheistische Religion (1939), el psicoanálisis, tal como se presenta hoy en día, no habría llegado a conformarse. Los textos citados, junto a diversas cartas, ensayos y conferencias testimonian el encuentro dislocador con la angustia de lo innombrable y su ulterior elaboración mediante la escritura. El psicoanálisis, a su vez, a través de estos repliegues se regenera y reproduce constantemente a sí mismo, recobra su fuerza especulativa y su poder crítico, abriéndose a otros discursos que, sin por ello obviar las diferencias insalvables con ellos, ahora reconoce como afines, enfatizando, sobre todo, su plasticidad y apertura incondicional al misterio y, en especial, al sentido.

Los textos freudianos, suerte de libro primordial del psicoanálisis contemporáneo, son la constancia de la inauguración de una relación completamente nueva y diferente al lenguaje. La sustitución de la mirada médica, apoyada en la función de la visión, por la escucha significó un vuelco decisivo e irreversible en la comprensión y el tratamiento de las neurosis al igual que para el estudio de lo social. Mediante esta transformación radical de la percepción clínica, que des- 
plazaría el foco de la atención hacia la narración, hacia el lenguaje mismo, se abriría la dimensión semántica, de la comprensión diferenciada de un psiquismo extraño y ajeno sobre el fondo del lenguaje. Por el hecho de estar entregados al lenguaje, a lo Simbólico, no estamos expuestos ni a la plenitud ni al vacío del ser, sino que nos movemos en un extraño entremezclamiento de los dos. Siempre nos queda un resto inexplicable, un residuo, que no se sigue de una incapacidad de nuestras posibilidades explicativas, sino que es constitutivo para que siguiera podamos conocer o desear. Este resto, presente como algo radicalmente in-nombrado, in-determinado, a-conceptual, es lo propiamente inconsciente. El énfasis freudiano en los vacíos, las omisiones y ausencias, las contradicciones y repeticiones indeseadas, el lapsus, el error y la química de las sílabas, subraya la estrecha vinculación entre la estructura de lenguaje e inconsciente. El surgimiento repentino de lo Ominoso, el asalto de lo críptico e indescifrable, de aquello que insistentemente se resiste a ser interpretado, es un antecedente importante para la consideración de lo inconsciente y de los límites de la interpretación psicoanalítica. Para concluir con una cita de Freud:

Si no estoy muy equivocado, por todos los caminos que hasta ahora emprendimos llegamos a la luz, al esclarecimiento y a la comprensión plena; a partir de este momento en que pretendemos penetrar más a fondo en los procesos anímicos envueltos en los sueños, todas las señas desembocan en la oscuridad ${ }^{37}$.

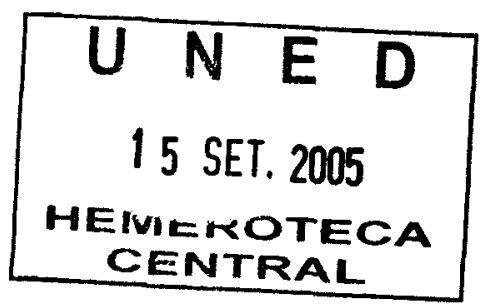

37 S. FREUD: La interpretación de los sueños (1900 [1899]), ed. cit., vol. V, p. 506. 